\title{
Caracterização morfológica do fruto, semente, fases da germinação e plântula de Ocotea paranaensis
}

Morphological characterization of fruit, seed, germination stages and seedling of Ocotea paranaensis

\author{
Sheilly Raquelly Prado de Paula*, Antonio Carlos Nogueira e Alessandro Camargo Angelo
}

Recebido em 03/02/2016 / Aceito em 26/04/2016

\section{RESUMO}

Ocotea paranaensis é uma espécie de baixa frequência na Mata Atlântica com registros de ocorrência apenas no estado do Paraná. Assim, este trabalho teve como objetivo descrever e ilustrar a morfologia de fruto e semente, fases da germinação e plântula de Ocotea paranaensis. Os frutos foram coletados em cinco matrizes no Parque Estadual das Lauráceas, Adrianópolis, PR. Para a descrição e ilustração do fruto e da semente foram analisadas 50 amostras. Para acompanhar as fases da germinação e o desenvolvimento da plântula, cinco repetições de 10 sementes foram colocadas em substrato vermiculita e postas em germinador Biomatic, a $30{ }^{\circ} \mathrm{C}$. O fruto é do tipo drupa, indeiscente, verde-claro a preto, epicarpo fino, glabro, liso, brilhante, mesocarpo carnoso, bastante espesso e endocarpo liso, coriáceo. A semente é exalbuminosa, globosa, tegumento liso, membranáceo, coloração castanho. O embrião é axial, plano-convexo, de coloração rosada. A germinação iniciou-se no $8^{\circ}$ dia se estendendo até o $60^{\circ}$ dia após a instalação do teste, sendo a plântula hipógea, criptocotiledonar, epicótilo cilíndrico com catáfilos verde-claro e protofilos simples, alternos, ápice agudo, base cuneada e coloração verde-claro. Os aspectos descritos e ilustrados mostraram-se confiáveis para a identificação da espécie em viveiros e em estudos de regeneração natural.

PALAVRAS-CHAVE: Lauraceae, espécie florestal nativa, morfologia vegetal

\footnotetext{
ABSTRACT

Ocotea paranaensis is a low frequency species in the Atlantic Forest and presents occurrence records

Universidade Federal do Paraná, Curitiba, PR, Brasil.

*Autor para correspondência <sheillyprado@gmail.com>
}

only in the state of Paraná. The present study aimed at describing and illustrating the fruit and seed morphology, germination stages and seedling of Ocotea paranaensis. The fruits used in this study were collected from 5 mother trees in Laurace State Park, Adrianópolis, PR. For the fruit and seed description and illustration, 50 random samples were analyzed. To monitor the germination stages and seedling development, 5 replicates with 10 seeds each were placed in vermiculite, and then put to germinate in a Biomatic germinator at $30^{\circ} \mathrm{C}$. The fruit is an indehiscent drupe, with coloration varying from bright green to black, with thin, hairless, smooth and shiny epicarp, quite thick, fleshy mesocarp, and smooth, coriaceous endocarp. The seed is exalbuminous, round, with smooth, membranous, with brown integument. The embryo is axial, convex flatenned of pink coloration. Germination started on the eighth day and went on up to the sixtieth day after the test was initiated. The seedling is hypogeal, cryptocotylar, presenting cylindrical epicotyl with bright green cataphylls and simple alternate protophylls, with acute apex, cuneate leaf base and light green color. The aspects described and illustrated in this study were proven to be reliable for the species identification in nurseries and also for natural regeneration studies.

KEYWORDS: Lauraceae, native forest species, plant morphology.

\section{INTRODUÇÃO}

Ocotea paranaensis Brotto, Baitello, Cervi \& E.P. Santos (Lauraceae) é uma espécie de dossel com ocorrência na Mata Atlântica, em áreas montanhosas da Serra do Mar Paranaense, entre 850 a 975 m de altitude. As árvores são dioicas, com altura próximo de 
14 metros e frutificação de julho a janeiro (BROTTO et al. 2010). A espécie é de baixa frequência no Bioma Mata Atlântica, e entre os estados do Brasil, ocorre apenas no estado do Paraná, único local onde a espécie foi até o momento coletada (BROTTO \& BAITELLO 2012), sendo, portanto, rara na Floresta Ombrófila Densa do Paraná (BROTTO 2010). De acordo com os critérios da IUCN (2001), a espécie pode ser considerada em perigo de extinção.

A grande dificuldade em estudos de fenologia e comportamento de uma espécie dentro de uma comunidade é a identidade das espécies (KUNIYOSHI 1983), o que evidencia, de modo geral, a importância dos estudos morfológicos de fruto, semente e plântula como ferramenta suporte na identificação destas. Além disso, estudos de caracterização morfológica, podem auxiliar na taxonomia, e também são fundamentais na silvicultura (AMORIM 1996), visto que frutos e sementes têm características básicas para a identificação de famílias e até mesmo do gênero, espécie ou variedade à qual a planta pertence (SILVA et al. 2008). Estas informações, aliadas às observações das plântulas, oferecem subsídios à interpretação de testes de germinação (OLIVEIRA 2009).

Vários trabalhos têm sido desenvolvidos para descrever e ilustrar aspectos morfológicos externos e internos de frutos, sementes e plântulas de diversas espécies, porém, para espécies da família Lauraceae há poucos registros. Alguns deles foram desenvolvidos por KUNIYOSHI (1983); MORAES \& PAOLI (1999); LEONHARDT et al. (2008) e PELEJA et al. (2013).

Através da descrição morfológica de frutos, sementes e plântulas, é possível obter informações sobre a germinação, viabilidade, armazenamento e métodos de semeadura, além de auxiliar nos estudos de regeneração natural (KUNIYOSHI 1983). Apesar da evidente importância deste ramo da ciência, bem como dos crescentes trabalhos que tem sido desenvolvidos para as mais variadas espécies de interesse, ainda existe carência de estudos sobre morfologia de frutos, sementes e plântulas voltados para espécies florestais nativas.

Diante do exposto, e devido às características morfológicas de frutos, sementes e plântulas de $O$. paranaensis serem pouco conhecidas, este trabalho teve por objetivo ilustrar e descrever as características morfológicas dos frutos e sementes, fases da germinação e plântula, a fim de que estas informações sejam úteis em programas de conservação da espécie.

\section{MATERIAL E MÉTODOS}

O trabalho foi realizado no Laboratório de Sementes Florestais do Departamento de Ciências Florestais da Universidade Federal do Paraná (UFPR), localizado no município de Curitiba, PR. Os frutos foram coletados no solo, embaixo de árvores matrizes localizadas no Parque Estadual das Lauráceas, Adrianópolis, PR. O material coletado foi conduzido até o laboratório, onde os frutos e sementes mal formadas e com injúrias foram eliminadas.

Foram utilizadas 50 amostras aleatórias para a descrição morfológica e ilustração dos frutos e sementes, realizando-se cortes transversais e longitudinais do material com lâmina de bisturi. Para as observações, foi utilizado microscópio estereoscópico. As dimensões (comprimento e maior diâmetro) de 100 sementes foram obtidas com auxílio de um paquímetro digital, com $0,05 \mathrm{~mm}$ de precisão. Foi considerado para o comprimento das sementes, a distância entre o ápice e a base, e o ponto de maior diâmetro.

Para a descrição morfológica do fruto foi observado o tipo e deiscência, além das características do pericarpo (espessura, pilosidade, textura, brilho e coloração), do mesocarpo (consistência, espessura e coloração) e do endocarpo (textura e coloração). Das sementes foram analisadas as seguintes características: forma, posição da micrópila, dimensões, presença ou ausência de endosperma, textura e cor. Para o embrião foram avaliados o tipo, a forma e a cor. Como referências para a descrição, foram consultados os trabalhos de SPJUT (1994) e BARROSO et al. (1999).

A fim de acompanhar o desenvolvimento das fases da germinação e o desenvolvimento das plântulas, cinco repetições de 10 sementes foram colocadas sob 25 gramas de vermiculita umedecidos com $50 \mathrm{ml}$ de água destilada, em recipientes tipo "gerbox" postos para germinar em germinador Biomatic, a $30{ }^{\circ} \mathrm{C}$ (luz constante). As observações aconteceram diariamente, sendo as ilustrações feitas a olho nu e realizadas desde a emissão da raiz até o desenvolvimento dos protofilos.

$\mathrm{Na}$ caracterização morfológica das plântulas foram analisadas as características da raiz: o tipo, a forma e a coloração; do hipocótilo: tamanho e espessura; do epicótilo: a forma, o tamanho, a pilosidade e a coloração; e dos protofilos: a textura, a forma, a nervação, a coloração e o tipo de borda, ápice 
e base. A descrição da plântula foi realizada conforme a nomenclatura proposta por KUNIYOSHI (1983).

\section{RESULTADOS E DISCUSSÃO}

\section{Caracterização morfológica de frutos}

Os frutos de Ocotea paranaensis (Figura 1-A) são do tipo drupa, indeiscentes e encerrado na cúpula. O epicarpo é fino, glabro, liso, brilhante e a coloração do fruto varia de acordo com o grau de maturação, modificando de verde-claro a preto, quando maduro. O mesocarpo é carnoso, sendo bastante espesso, de coloração marrom claro quando maduro. O endocarpo é liso, coriáceo e coloração castanho-claro. De acordo com BROTTO et al. (2010), os frutos de O. paranaensis têm dimensões de $15 \times 15 \mathrm{~mm}$, são globosos, com cúpula de $7 \times 5 \mathrm{~mm}$, sub-hemisférica, margem simples.

Considerando a classificação proposta por BARROSO et al. (1999) os frutos característicos da família Lauraceae são do tipo bacóide. Porém, esta descrição têm sido contestada para espécies da família, uma vez que alguns autores afirmam que os frutos dessas canelas devem ser considerados como drupas e não bagas. RAGGI (2008) afirma que o gênero Ocotea é caracterizado por apresentar fruto do tipo baga com cúpula; CARVALHO (2008) apresenta que Nectandra membranacea tem fruto tipo baga; para CARVALHO (2003) os frutos de Ocotea puberula são do tipo bacáceo; GIANNERINI et al. (2007) caracterizam os frutos das espécies do gênero Ocotea como bacáceo; e LORENZI (2008, 2009a e 2009b), conceitua todas as espécies da família Lauraceae incluídas em suas edições, como sendo do tipo baga, menos as espécies Nectandra lanceolata e Persea venosa, que considera drupa, dando indícios da dúvida sobre o tipo de fruto das espécies da família Lauraceae pelo próprio autor.

De acordo com GOLA et al. (1965), os frutos do tipo bacóide tem o pericarpo carnoso em toda a sua espessura, normalmente provém de gineceus de vários carpelos e apresentam tegumentos resistentes, podendo conter uma a várias sementes. Já a drupa se caracteriza por ter a semente protegida por um endocarpo duro, lenhoso. SPJUT (1994) conceitua baga como fruto indeiscente e internamente carnoso, e drupa um fruto com uma ou mais sementes fechadas dentro de um "caroço". ESAU (1974) cita que frutos conhecidos como carnosos são bagas, nas quais todo o tecido fundamental é carnoso, sendo a drupa um fruto carnoso derivado de um ovário súpero caracterizado por um endocarpo pétreo, mesocarpo carnoso e exocarpo fino.

Segundo SOUZA(2006), na literatura botânica, os frutos das espécies de canelas, como Ocotea puberula e Nectandra megapotamica, são registrados como baga. Entretanto, a investigação anatômica do desenvolvimento de seus frutos mostrou que o tecido esclerenquimático que envolve a semente, interpretado como tegumento seminal, é na verdade a epiderme interna do pericarpo ou endocarpo. Durante o desenvolvimento, as células epidérmicas do pericarpo jovem alongam-se radialmente, diferenciamse em macroesclereídes e contatam firmemente com a epiderme da testa, formando uma estrutura única vulgarmente chamada "caroço" e encontrada caracteristicamente em drupas. Sendo assim, nessas espécies de Lauraceae quando se retira a semente do fruto maduro, o endocarpo rígido permanece aderido ao tegumento seminal, parecendo ao observador inadvertido a epiderme da testa. KUNIYOSHI (1983) caracteriza fruto do tipo drupa para Cinnamomum vesiculosum, Nectandra megapotamica, Ocotea corymbosa e Ocotea porosa, todas estas espécies da família Lauraceae.

\section{Caracterização morfológica de sementes}

A semente (Figura 1-B) possui forma globosa, apresentando junto ao ápice um pequeno poro, que internamente corresponde ao local da micrópila. As dimensões médias das sementes (com envoltório) foram: comprimento $12,96 \mathrm{~mm}$, apresentando $\mathrm{CV}=5,25 \%$ e maior diâmetro $11,81 \mathrm{~mm}$ e $\mathrm{CV}=5,54 \%$ (Tabela 1). Valores médios próximos aos encontrados para O. paranaensis foram descritos por KUNIYOSHI $(1983)$ para Ocotea porosa, com comprimento de 15,7 mm e 14,2 mm de diâmetro. Já valores médios mais baixos foram encontrados para sementes de Ocotea corymbosa com 2 a $5 \mathrm{~mm}$ de comprimento e 1 a 2,5 mm de diâmetro (CARVALHO 2008) e também para sementes de Ocotea puberula que apresentaram dimensões de 4 a $10 \mathrm{~mm}$ de comprimento e 2 a $5 \mathrm{~mm}$ de diâmetro (CARVALHO 2003).

A semente é exalbuminosa, o tegumento é de superfície lisa, membranáceo aderido ao endocarpo e coloração castanho, o embrião é axial e os cotilédones são plano-convexos, de coloração rosada na superfície e na porção apical é branca a creme (Figura 1-C; D).

BARROSO et al. (1999) descrevem o embrião de Cryptocarya (Lauraceae) como glabro, crasso, e observaram embrião com cotilédones vermelhos 

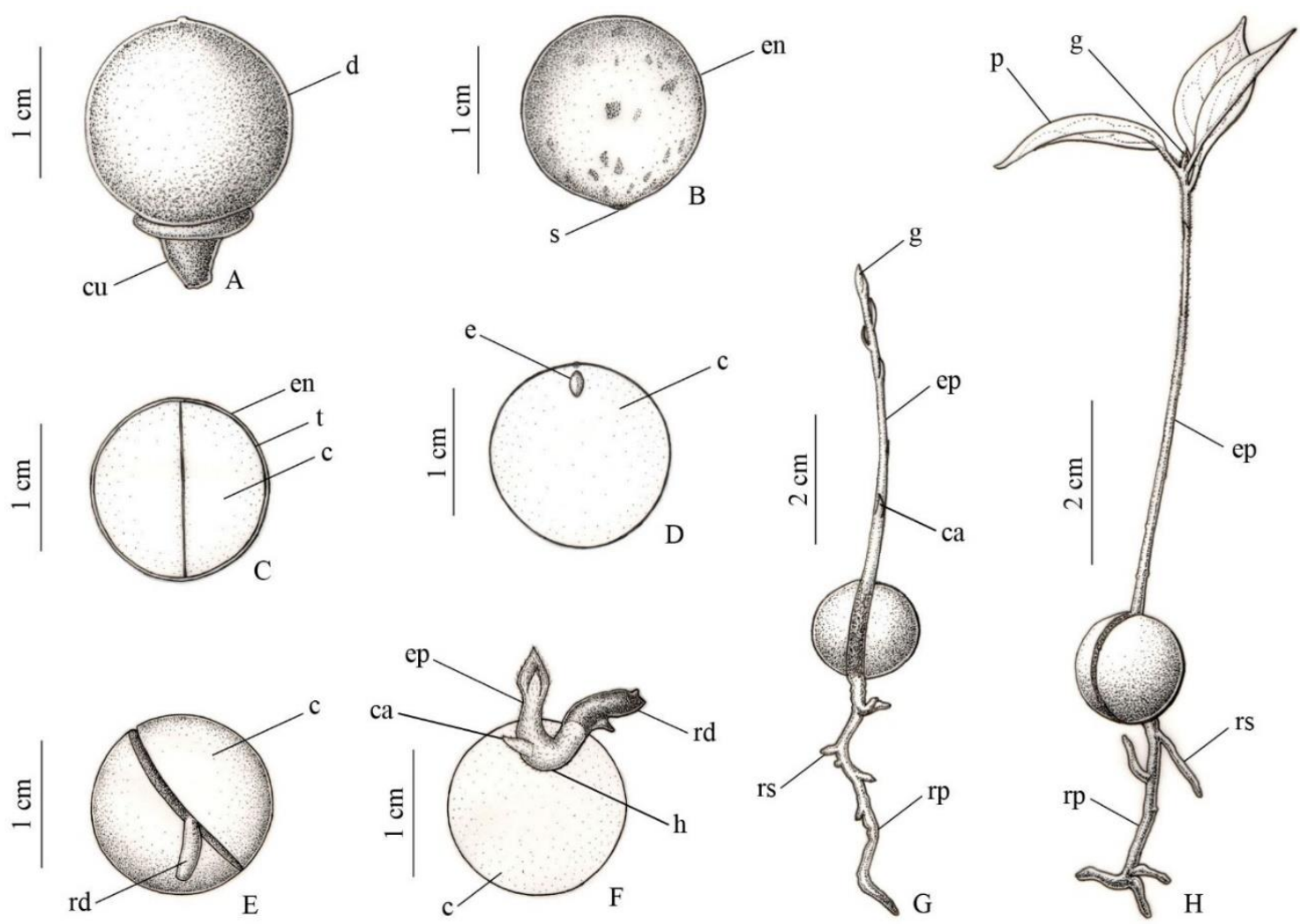

Figura 1 - Fruto, semente e plântula de Ocotea paranaensis. A - fruto, B - semente, C - secção longitudinal da semente, D - secção transversal da semente, E-F - fases da germinação, G-H - plântula. c - cotilédone, cu - cúpula, ca - catáfilos, d - drupa, , e - eixo embrionário, en - endocarpo, ep - epicótilo, g - gema, $\mathrm{h}$ - hipocótilo, $\mathrm{p}$ - protofilos, $\mathrm{rd}$ - radícula, rp - raiz principal, $\mathrm{rs}$ - raízes secundárias, $\mathrm{s}$ - saliência no endocarpo que internamente corresponde à micrópila, $\mathrm{t}$ - tegumento. Escala $\mathrm{em} \mathrm{cm}$.

Figure 1 -Fruit, seed and seedling of Ocotea paranaensis. A - fruit, B - seed, $C$ - seed longitudinal section, $D$ - seed cross section, E-F - stages of germination, $G-H$ - seedling. c - cotyledon, cu - dome, ca - catáfilos, $d$ - drupe, e - embryonic axis, en - endocarp, ep - epicotyl, $g$ - button, $h$ - hypocotyl, $p$ - protophylls, $r d$-radicle, $r p$-main roots, $r s$ - secondary roots, $s$-overhang of endocarp internally is the micropyle, $t$-integument. Scale in $\mathrm{cm}$.

para Ocotea (Lauraceae), apesar da grande maioria dos cotilédones apresentarem-se incolores ou esbranquiçados.

As sementes de $O$. paranaensis apresentam dimensões médias. Os valores do coeficiente de variação foram baixos e não variaram entre as características comprimento e maior diâmetro, indicando a relativa homogeneidade da amostra obtida (Tabela 1).

\section{Morfologia das fases da germinação e plântula}

A germinação é hipógea, criptocotiledonar e inicia-se no oitavo dia se estendendo até o $60^{\circ}$ dia. A germinação inicia-se pela emissão da radícula na região da micrópila. A radícula é de cor creme e com finíssimas camadas distribuídas na superfície
(Figura 1-E). Internamente, entre os cotilédones, o hipocótilo junto à raiz engrossa, separando os cotilédones, possibilitando o desenvolvimento do epicótilo com a gema apical (Figura $1-\mathrm{F}$ ). No $24^{\circ}$ dia ocorre o crescimento do epicótilo, que se expande e no $52^{\circ}$ dia formam os primeiros protofilos. A emissão de novos protofilos se dá no $59^{\circ}$ dia.

A raiz é axial, cilíndrica, com raízes secundárias distribuídas, coloração castanho-claro com poucos pêlos absorventes na superfície. $O$ hipocótilo é curto, grosso, quase imperceptível e articulase com os cotilédones. Os cotilédones se situam lateralmente ao eixo embrionário, encobertos pelos envoltórios (endocarpo + tegumento). O epicótilo é bem desenvolvido, cilíndrico, ereto, longo (07 - 08 $\mathrm{cm}$ de comprimento), verde-claro, branco próximo 
Tabela 1 - Comprimento e maior diâmetro das sementes de Ocotea paranaensis. Table 1 - Length and larger diameter of the seeds of Ocotea paranaensis.

\begin{tabular}{ccccc}
\hline Dimensões (mm) & Mínimo & Média & Máximo & Coeficiente de Variação (\%) \\
\hline Comprimento & 10,94 & 12,96 & 14,22 & 5,25 \\
Maior diâmetro & 10,36 & 11,81 & 13,20 & 5,54
\end{tabular}

à articulação dos cotilédones e tons avermelhados no ápice, pubérulo com tricomas alvos em toda sua extensão e catáfilos com disposição espiralada. Os catáfilos já estão presentes a partir do nó cotiledonar e apresentam cor verde com leve pigmentação avermelhada (Figura 1-G).

Os protofilos são simples, alternos, peciolados, contorno elíptico, de ápice agudo, base cuneada, membranáceos, cobertos por papilas alvas na face abaxial e glabra na face adaxial, de coloração verdeclaro. O padrão de nervação é broquidódromo apresentando nervura principal e secundárias subsalientes em ambas as face e 6-7 pares de nervuras secundárias de coloração mais clara que o limbo (Figura 1-H).

BROTTO et al. (2010), descreveram $O$. paranaensis com ápice da folha acuminado, apresentando de 4-6 pares de nervuras. COUTINHO et al. (2006) descreveram os protofilos de Ocotea gardneri de consistência coriácea, contorno elíptico a oval-elíptico, ápice acuminado, base simétrica e arredondada, discolor, verde-escuro, brilhante, com a venação levemente proeminente adaxial, verde claro, opaco, e fortemente proeminente abaxial.

\section{CONCLUSÕES}

As sementes mediram em média $12,96 \mathrm{~mm}$ de comprimento e $11,81 \mathrm{~mm}$ de maior diâmetro.

O fruto é do tipo drupa, indeiscente, passando pelas colorações verde-claro a preto, com epicarpo fino, glabro, liso, brilhante, mesocarpo carnoso, bastante espesso e com endocarpo liso, coriáceo.

A semente é exalbuminosa, globosa, tegumento liso, membranáceo, coloração castanho, sendo o embrião axial, plano-convexos, de coloração rosada.

A germinação iniciou-se no oitavo dia se estendendo até o $60^{\circ}$ dia após a instalação do teste, sendo a plântula hipógea, criptocotiledonar, epicótilo cilíndrico com catáfilos de cor verde-claro e protofilos simples, alternos, de ápice agudo, base cuneada e coloração verde-claro.
Os aspectos descritos e ilustrados mostraram-se confiáveis para a identificação da espécie em viveiros e também para estudos de regeneração natural.

\section{REFERÊNCIAS}

AMORIM IL. 1996. Morfologia de frutos, sementes, germinação, plântulas e mudas de espécies florestais da região de Lavras - MG. Dissertação (Mestrado em Engenharia Florestal). Lavras: UFL. 77p.

BARROSO GM et al. 1999. Frutos e sementes: morfologia aplicada à sistemática de dicotiledôneas. Viçosa: Ed. UFV. 443p.

BROTTO ML. 2010. Estudo taxonômico do gênero Ocotea Aubl. (Lauraceae) na Floresta Ombrófila Densa no Estado do Paraná, Brasil. Dissertação (Mestrado em Botânica). Curitiba: UFPR. 92p.

BROTTO ML \& BAITELLO JB. 2012. Uma espécie nova de Lauraceae da floresta atlântica do Brasil. Rodriguésia 63: 579-585.

BROTTO ML et al. 2010. Uma nova espécie de Ocotea (Lauraceae) para o Brasil. Rodriguésia 61: 57-60.

CARVALHO PER. 2003. Espécies arbóreas brasileiras. vol.1. Colombo: Embrapa Florestas. 1039p.

CARVALHO PER. 2008. Espécies arbóreas brasileiras. vol.3. Colombo: Embrapa Florestas. 593p.

COUTINHO DF et al. 2006. Morfo-anatomia foliar de Ocotea gardneri (Meisn.) Mez (Lauraceae-Lauroideae).

Revista Brasileira de Farmacognosia 16: 178-184.

ESAU K. 1974. Anatomia das plantas com sementes. São Paulo: Ed. Blucher. 312p.

GOLA G et al. 1965. Tratado de Botânica. Barcelona. 2.ed. Madrid: Ed. Labor. 1160p.

GIANNERINI AC et al. 2007. O gênero Ocotea Aubl. (Lauraceae) no Parque Nacional do Itatiaia, Brasil. Pesquisa Botânica 58: 283-330.

IUCN. 2001. The International Union for Conservation of Nature (IUCN) red list categories v. 3.1. Disponível em: http://www.iucnredlist.org/apps/redlist/static/categories criteria 3 1. Acesso em: 2 jun. 2015.

KUNIYOSHI YS. 1983. Morfologia da semente e da germinação de 25 espécies arbóreas de uma Floresta com Araucária. Dissertação (Mestrado em Ciências Florestais). Curitiba: UFPR. 233p.

LEONHARDT C et al. 2008. Morfologia e desenvolvimento de plântulas de 29 espécies arbóreas nativas da área da 
Bacia Hidrográfica do Guaíba, Rio Grande do Sul, Brasil. Iheringia Série Botânica 63: 5-14.

LORENZI H. 2008. Árvores Brasileiras: Manual de Identificação e Cultivo de Plantas Arbóreas Nativas do Brasil. 5.ed. São Paulo: Instituto Plantarum. 384p.

LORENZI H. 2009a. Árvores Brasileiras: Manual de Identificação e Cultivo de Plantas Arbóreas Nativas do Brasil. 3.ed. São Paulo: Instituto Plantarum. 384 p.

LORENZI H. 2009b. Árvores Brasileiras: Manual de Identificação e Cultivo de Plantas Arbóreas Nativas do Brasil. 2.ed. São Paulo: Instituto Plantarum. 384p.

MORAES PLR \& PAOLI AAS. 1999. Morfologia e estabelecimento de plântulas de Cryptocarya moschata Nees, Ocotea catharinensis Mez e Endlicheria paniculata (Spreng.) MacBride - Lauraceae. Revista Brasileira Botânica 22: 287-295.

OLIVEIRA RG. 2009. Germinação de sementes e crescimento inicial de plântulas de Eschweilera ovata (Cambess.) Miers., Trema micranta (L.) Blume. e Ficus tomentella Miquel. Dissertação (Mestrado em Ciências Florestais). Recife: UFRPE. 67p.

PELEJA VL et al. 2013. Fenologia reprodutiva e morfologia do fruto e plântulas de Aniba parviflora (Lauraceae). In: $64^{\circ}$ Congresso Nacional de Botânica. Resumos... Belo Horizonte: Sociedade Botânica do Brasil. p.10.

RAGGI L. 2008. Estudo da composição química e das atividades biológicas de óleos voláteis de espécies de Lauraceae, em diferentes épocas do ano. Dissertação (Mestrado em Biodiversidade Vegetal e Meio Ambiente). Instituto de Botânica da Secretaria de Estado do Meio Ambiente, São Paulo. 67p.

SILVA KB et al. 2008. Morfologia de frutos, sementes, plântulas e plantas de Erythrina velutina Willd., Leguminoseae - Papilionideae. Revista Brasileira de Sementes 30: 104-114.

SOUZA LA. 2006. Fruto. In: SOUZA LA et al. Anatomia do fruto e da semente. Ponta Grossa: Ed. UEPG. 196p.

SPJUT RW. 1994. A Systematic Treatment of Fruit Types. Bronx: NY. 181p. 